\title{
CLASES SOCIALES Y PEDAGOGIAS: VISIBLES E INVISIBLES*
}

A continuación examinaré algunos de los presupuestos y el contexto cultural de una forma de pedagogía para el pre-escolar y la escuela infantil, una forma que tiene al menos las siguientes características:

1) Donde el control del maestro sobre el niño es implícito en lugar de ser explicito.

2) Donde el maestro organiza idealmente el contexto que se espera el niño explore y reorganice.

3) Donde dentro del contexto organizado, el niño aparentemente tiene amplios poderes sobre lo que selecciona, sobre cómo él estructura y sobre la escala del tiempo de sus actividades.

4) Donde el niño aparentemente regula sus propios movimientos y relaciones sociales.

5) Donde hay un reducido énfasis sobre la transmisión y adquisición de habilidades específicas ${ }^{29}$.

6) Donde los criterios para la evaluación de la pedagogía son múltiples, difusos y no son fácilmente mensurables.

\section{Pedagogía invisible y la educación infantil}

Uno puede caracterizar esta pedagogía como una pedagogía invisible. En términos de los conceptos de clasificación y enmarcación, esta pedagogía se realiza mediante clasificación débil y mediante enmarcación débil. Las pedagogías visibles se realizan mediante clasificación y enmarcación fuertes. La diferencia básica entre las pedagogías visibles y las invisibles yace en la manera en la cual se transmiten los criterios y en el grado de especificidad de éstos. Entre más implícita sea la modalidad de transmisión y entre más difusos los criterios, más invisible es la pedagogía; entre más específicos sean los criterios más explícita es la manera de su transmisión y más visible la pedagogía. Estas definiciones se amplían a continuación.

\section{Definiciones formales de las pedagogías visibles e invisibles}

Aquí propondremos que la relación social crucial de reproducción cultural es aquella que se realiza entre transmisores y adquirientes. Sugerimos que esta relación está regulada por tres rasgos básicos:

\footnotetext{
* Tomado de Class Codes and Control; Vol. 3 Towards a Theory of Educational Transmissions. London: R.K.P. traducido con permiso del autor por Mario Díaz.

${ }^{29}$ Esto plantea una serie de problemas. Primero, las habilidades no pueden considerarse como algo separado del contexto de su transmisión, de sus relaciones con otras habilidades, ni de sus funciones de creación, mantenimiento, modificación y cambio de una cultura. Las habilidades y sus relaciones entre sí son competencias específicamente culturales. La forma de su transmisión socializa al niño en sus usos contextuales. Así, la unidad de análisis no puede ser, simplemente, una competencia abstracta como leer, escribir o contar, sino, la estructura de las relaciones sociales que produce estas competencias especializadas. La formulación "donde hay un reducido énfasis sobre la transmisión y adquisición de habilidades específicas" podría ser mal-interpretada, ya que sugiere que en el contexto bajo discusión existen pocos repertorios especializados de la cultura. Resulta mejor interpretar la formulación indicando su énfasis sobre las interrelaciones entre habilidades que están, en cierto modo, débilmente clasificadas y débilmente enmarcadas. En esta forma, cualquier habilidad o conjunto de habilidades se refiere a los rasgos generales de la socialización.
} 
1) Jerarquía. Deben existir reglas formales y/o informales, por medio de las cuales, se constituye inicialmente la relación social. Estas reglas regulan lo que debe ser un transmisor y lo que debe ser un adquiriente (un aprendiz). Se espera que el aprendiz aprenda a ser un tipo particular de aprendiz y que el transmisor aprenda a ser un tipo particular de transmisor. Estas reglas determinan la forma jerárquica de la transmisión. Ellas establecen sus reglas de conducta.

2) Reglas de secuencia. Cualquier transmisión se extiende en el tiempo. Como consecuencia, algo ocurre antes y algo viene después. Deben existir reglas que regulen el progreso de la transmisión en el tiempo y que establezcan la secuencia. Llamaremos al principio que regula la transmisión, reglas de secuencia.

3) Criterios. Cualquier relación de transmisión/adquisición vincula, necesariamente, la transferencia de criterios con los cuales se espera que el aprendiz (adquiriente) controle, explore y evalúe su propia conducta y la de los demás.

Estamos argumentando que la jerarquía, las reglas de secuencia y los criterios constituyen los rasgos básicos de cualquier relación de transmisión y adquisición, y por lo tanto son rasgos cruciales para la educación. Consideramos además que la forma que toma la relación jerárquica afecta tanto las reglas de secuencia como los criterios. Sobre la base de estos tres rasgos, podemos definir de manera más específica las transmisiones o pedagogías visibles e invisibles.

\section{1) Jerarquía}

Las reglas de jerarquía pueden ser explícitas o implícitas. Si las reglas son explícitas, entonces las relaciones entre el transmisor y el adquiriente son relaciones de dominación y subordinación no ambiguas. Sin embargo, las reglas de jerarquía pueden ser implícitas. En este caso la relación de dominación/subordinación no es una relación claramente definida. El aprendiz parece tener gran control sobre la regulación de sus movimientos, actividades y comunicaciones. Esencialmente, la jerarquía implícita enmascara las relaciones de poder. Cuando la jerarquía es implícita, el aprendiz probablemente está sujeto a la regulación de sus compañeros. Consideremos como ejemplo las ilustraciones del "Plowden Report" donde el maestro raras veces está presente y los niños aparecen en primer plano.

\section{2) Reglas de secuencia}

Las reglas de secuencia que regulan la transmisión pueden ser explícitas o implícitas. $\mathrm{Si}$ las reglas de secuencia son explícitas, entonces (si estamos considerando una escuela) dichas reglas regulan públicamente lo que un niño de cinco, seis, siete años, debería ser capaz de hacer. Las reglas de secuencia regulan el desenvolvimiento del syllabus, los currícula y el sistema de evaluación. Cuando las reglas de secuencia son explícitas existe un concepto explícito del progreso del niño de tal forma que éste es en algún sentido consciente de, o tiene conocimiento del, estado futuro esperado de su conciencia. Sin embargo, puede que el alumno se identifique o no se identifique con lo que de él se espera. Si las reglas de secuencia son implícitas el aprendiz nunca puede conocer los principios de su propio progreso. Sólo el transmisor los conoce. Cuando las reglas de secuencia son implícitas el syllabus y el curriculum son definidos con menos claridad. Cuando las reglas de secuencia son implícitas, entonces, el género y la edad cronológica del niño no constituyen rasgos distintivos fuertes de dichas reglas. Finalmente, cuando las reglas de secuencia son implícitas sólo el transmisor las conoce. 
Cuando las reglas de secuencia son implícitas, éstas, se derivan de diferentes áreas y teorías especiales de la psicología del desarrollo infantil, y el transmisor interpretará la conducta del niño a la luz de estas teorías. El transmisor buscará signos que den muestra de los estadios de desarrollo del niño, ya sean éstos lingüísticos sociales, intelectuales o afectivos, y responderá y organizará los contextos y contenidos para el niño de acuerdo con la interpretación que hace de estos signos. De esta manera, las reglas de secuencia implícitas crearían teorías de los signos. En este caso, el significado del signo de progreso del niño puede ser conocido únicamente por el maestro y no por el alumno. Cuando las reglas de secuencia son explicitas, el niño es consciente de los signos que indican su progreso y puede leer el significado de estos signos. Articuladas a las reglas de secuencia también encontramos el ritmo de la transmisión. (velocidad esperada de la adquisición). En general, aunque no siempre, las reglas de secuencia explícitas son iguales a un "ritmo" fuerte, y las reglas de secuencia implícitas son iguales a un ritmo débil de la transmisión. Tenemos, pues, que las reglas de secuencia pueden ser explícitas o implícitas.

\section{3) Criterios}

En la misma forma en que las reglas de secuencia y de jerarquía pueden ser explícitas o implícitas, los criterios pueden ser explícitos y específicos, o implícitos, múltiples o difusos. Cuando la transmisión realiza criterios explícitos, entonces el transmisor continuamente está haciendo consciente al adquiriente tanto en forma oral como escrita acerca de lo que no está presente en su producción. Consideremos, por ejemplo, una escuela infantil de hace 50 años, donde los niños están sentados en sus pequeñas sillas individuales y trabajando en pequeños pupitres organizados en filas. Los niños tienen una pequeña hoja de papel, una caja pequeña de acuarelas y un pincel. ¿Qué hacen? Ellos están elaboran facsímiles del exterior de la escuela. Ellos están aprendiendo un código estético reproductivo. Probablemente estén pintando figuras, casas, etc. El maestro mira el producto de un niño y dice "Esta es una casa muy bonita, pero ¿dónde está la chimenea?" o "Esta casa no tiene ventanas" o "ese hombre sólo tiene tres dedos", etc. Aquí se está haciendo consciente al niño de lo que ha omitido en su producción, y lo que se ha omitido se ha hecho explícito y específico y está sujeto a una evaluación muy bien graduada.

En algunas de las escuelas infantiles de hoy, los niños tienen una hoja de papel grande, y en vez de una pequeña caja de acuarelas tienen un conjunto de medios a través de los cuales su imaginación visual puede ser revelada momentáneamente. Esto supuestamente no constituye un código estético reproductivo sino un código estético productivo. Es probable que en este caso el maestro diga "¿Qué es esto?”, y no cree explícitamente en el niño la conciencia de lo que se ha omitido en el producto; es más probable que el maestro haga esto de manera indirecta, en un contexto de ayuda difusa y general. Cuando la transmisión manifiesta criterios implícitos, es como si el aprendiz fuera la fuente de estos criterios.

Podemos ahora, definir formalmente las transmisiones o pedagogías visibles o invisibles. (Visible e invisible se refieren a la transmisión desde el punto de vista del adquiriente, y no a la transmisión desde el punto de vista del transmisor). Una pedagogía visible se crea mediante:

1) Una jerarquía explícita;

2) Reglas de secuencia explícitas; y

3) Criterios explícitos y específicos. 
La regla subyacente de este tipo de pedagogía es: "Las cosas deben estar separadas". La pregunta aquí es, ¿por qué y para qué propósitos? La clasificación fuerte se realiza mediante las pedagogías visibles (enmarcación fuerte).

Una pedagogía invisible se crea mediante:

1) Una jerarquía implícita;

2) Reglas de secuencia implícitas; y

3) Criterios implícitos.

La regla subyacente aquí es: "Las cosas deben estar juntas". La pregunta aquí es, ¿qué cosas y para qué propósitos? La clasificación débil se realiza mediante las pedagogías invisibles (enmarcación débil) pero esto no necesariamente quiere decir que la clasificación débil dé siempre origen a una enmarcación débil. Finalmente, con el propósito de evitar confusión, es importante tener absolutamente claro que aunque existen muchas implicaciones en relación con el concepto de pedagogía invisible, aquí, éste se usa en el contexto de los primeros años de la vida infantil tanto en la familia como en la escuela. Los códigos integrados son estructuralmente equivalentes a los niveles secundarios y superiores.

\section{Discusión}

Si la pedagogía es invisible, ¿qué aspectos del niño son de alta visibilidad para el maestro? Sugerimos dos aspectos. El primero surge de la inferencia que el maestro hace del estadio de desarrollo del niño a partir de su conducta continua. Esta inferencia se refiere al concepto de aptitud. El segundo aspecto se refiere a la conducta externa del niño y es conceptualizado por el maestro como actividad (ocupación). El niño debiera estar ocupado haciendo cosas. Estos aspectos interiores (aptitud) y exteriores (ocupación) del niño pueden transformarse en el concepto "listo para hacer". El maestro infiere el estado de aptitud a partir de la actividad del niño, en la medida en que la aptitud se revela en su actividad presente y bosqueja la actividad futura.

Conviene anotar brevemente un punto que desarrollaremos más tarde. En la misma forma en que la lectura libera al niño del maestro y lo socializa en el aprendizaje solitario y privatizado de un pasado anónimo explícito (esto es, el texto escolar), así mismo, el niño ocupado (el niño que hace) se libera del maestro pero se socializa en un presente interactivo continuo en el cual el pasado (esto es la teoría pedagógica del maestro) está invisiblemente presente y de esta manera implícito. De esta manera, un niño no-activo (que no hace) en la pedagogía invisible es el equivalente de un niño que no lee en la pedagogía visible. (sin embargo, un niño que no lee puede estar en mayor desventaja y experimentar mayor dificultad que un niño no activo (que no hace).

El concepto básico de la pedagogía invisible es el juego. Este no es el lugar para someter este concepto a un análisis lógico, sin embargo, pueden anotarse los siguientes puntos:

1) El juego es el medio por el cual el niño se exterioriza al maestro. Así, mientras más juegue el niño y más amplio sea el rango de sus actividades, más amplias serán las características de su persona que estén expuestas al examen del maestro. En esta forma, el juego es un concepto fundamental que tiene como conceptos subordinados el de "aptitud" y el de "actividad" (hacer). A pesar de que no todas las formas de actividad 
se pueden considerar como juego (golpear a otro niño, por ejemplo), la mayor parte puede caracterizarse de esta manera.

2) El juego no solamente describe una actividad, sino que también contiene una evaluación de esa actividad. Así pues, existe un juego productivo y un juego menos productivo, un juego obsesivo y un juego de libre alcance; un juego solitario y un juego social. El juego no es sólo una actividad; éste implica una teoría a partir de la cual se derivan una interpretación, una evaluación y un diagnóstico, y la cual también indica un progreso; una teoría que el niño nunca puede conocer en la misma forma que puede conocer los criterios que son realizados en una pedagogía visible. El juego implica una teoría potencialmente abarcadora pues cubre casi, si no todo, el hacer y el no-hacer del niño. Como consecuencia, debe construirse una larga cadena de inferencias para conectar la teoría con cada actividad o no-actividad ("un hacer" y "un no-hacer"). La teoría da origen a una vigilancia del niño total aunque invisible porque relaciona sus disposiciones internas con todos sus actos externos. La "espontaneidad" del niño se filtra mediante esta vigilancia y luego se modela implícitamente de acuerdo con una interpretación, evaluación y diagnóstico.

3) Tanto el medio como los fines del juego son múltiples y cambian con el tiempo. A causa de esto, los estímulos deben ser, en general, altamente abstractos y susceptibles de ser contextualizados por el niño. De esta manera, se facilita el hacer particular o único de cada niño. Es claro que el juego estimula a cada niño a hacer sus propias marcas. Algunas veces, sin embargo, el estímulo puede ser muy perceptible como cuando el niño es invitado a tocar una hoja, o un pedazo de terciopelo; sin embargo, lo que se espera es una respuesta única del niño a sus propias sensaciones. ¿Cuál es el código para leer las marcas? Es un código que el niño nunca puede saber pero que adquiere implícitamente. ¿Cómo hace el niño esto?

4) La base social de esta teoría del juego no es un acto individualizado, sino un acto personalizado, cuya relación social no es fuerte, sino débilmente enmarcada. Su estructura social puede caracterizarse como una estructura de solidaridad orgánica personalizada abierta, pero de solidaridad mecánica encubierta. Las pedagogías visibles crean estructuras sociales que pueden caracterizarse como "solidaridad orgánica individualizada encubierta" y "solidaridad mecánica abierta"30. (Véase discusión posterior).

5) En esencia, el juego es trabajo y el trabajo es juego. Aquí podemos comenzar a ver los orígenes de clase de la teoría. Para la clase obrera el trabajo y el juego están fuertemente clasificados y fuertemente enmarcados; para ciertos sub-grupos de la clase media el trabajo y el juego están clasificados y enmarcados débilmente. Para estos sub-grupos no se puede trazar una línea estricta de demarcación entre trabajo y juego. El trabajo conlleva lo que a menudo se denomina satisfacciones "intrínsecas" y por lo tanto no está confinado a un solo contexto. Sin embargo, desde otro punto de vista, el trabajo ofrece la oportunidad del narcisismo simbólico el cual combina el placer interior con el prestigio exterior. Para ciertos sub-grupos de la clase media, el trabajo es un acto personalizado dentro de una estructura social privatizada. Estos puntos serán desarrollados más adelante.

\footnotetext{
${ }^{30}$ Esto puede verse muy claramente si observamos un aula de clase; las pedagogías visibles crean contextos de aprendizaje homogéneos; las pedagogías invisibles crean contextos de aprendizaje diferenciados. 


\section{Teorías del Aprendizaje y Pedagogía Invisible}

Estamos ya en posición de analizar los principios que subyacen a la selección de teorías del aprendizaje que las pedagogías del pre-escolar y de la escuela infantil pueden adoptar. Tales pedagogías probablemente adopten cualquier teoría del aprendizaje que tenga las siguientes características:

1) Las teorías en general tratarán de encontrar universales $y$, en esta forma, probablemente sean teorías acerca del desarrollo y acerca de la secuencia. Un contexto de aprendizaje particular es de interés sólo y en tanto permita aclarar el problema de la secuencia. Es posible que tales teorías descansen sobre profundas concepciones biológicas.

2) El aprendizaje es un acto tácito e invisible. Su progreso no está facilitado por un control público explícito.

3) Las teorías tenderán a abstraer la biografía personal del niño y el contexto local de su biografía cultural y contexto institucional.

4) En cierta forma, las teorías ven a los agentes socializantes como potencialmente, si no realmente, peligrosos, pues ellos incorporan un concepto del socializado centrado en el adulto y por lo tanto mistificado. Los modelos ejemplares son, relativamente, de poca importancia y, en consecuencia, las diversas teorías apuntan de maneras diferentes hacia relaciones sociales jerárquicas implícitas más que a relaciones explícitas. En realidad, el modelo socializante que se impone se transforma en facilitador.

5) De esta manera, las teorías pueden verse como interruptores de reproducción cultural $\mathrm{y}$, por lo tanto, han sido consideradas por algunos como progresistas, y aún revolucionarias. Las nociones de tiempo del niño remplazan a las nociones de tiempo del adulto. Las nociones de espacio del niño remplazan a las nociones de espacio del adulto; la facilitación remplaza a la imposición y la acomodación remplaza a la dominación.

Indicaremos, ahora, un grupo de teorías que, a pesar de sus múltiples diferencias, presentan, a un nivel más abstracto, todas, o casi todas, las cinco condiciones mencionadas previamente.

$\begin{array}{llllll}\text { Piaget } & 1 & 2 & 3 & 4 & 5 \\ \text { Freud } & 1 & 2 & 3 & 4 & 5 \\ \text { Chomsky } & 1 & 2 & 3 & 4 & 5 \\ \begin{array}{l}\text { Teorías etológicas del aprendizaje } \\ \text { Crítico }\end{array} & 1 & 2 & 3 & & \\ \text { Gesalt } & & 2 & 3 & 4 & 5\end{array}$

Lo interesante consiste en que estas teorías forman un grupo algo extraño, si no contradictorio. Estas teorías son, a menudo, seleccionadas para justificar un elemento específico de la pedagogía. Ellas constituyen, en cierta forma, la teleología de la escuela infantil. Nosotros podemos observar cómo el concepto crucial del juego y sus conceptos 
subordinados de aptitud y actividad encajan bien con las teorías expuestas arriba. También podemos notar cómo la invisibilidad de la pedagogía encaja con el acto tácito e invisible del aprendizaje. Igualmente podemos ver que el movimiento pre-escolar y de la escuela infantil es, desde cierto punto de vista, un movimiento progresista, revolucionario y colonizante en sus relaciones con los padres, y en sus relaciones con los niveles superiores de educación. Este movimiento es antagónico, por diferentes razones, a las familias de la clase media y de la clase obrera, pues ambas crean una deformación del niño. Es también antagónico a los niveles superiores de educación a causa de su oposición fundamental a sus conceptos de aprendizaje y de relaciones sociales. Aquí podemos notar que, como resultado, el niño es abstraído de su familia y de sus contextos educativos futuros.

Es de central importancia señalar que esta pedagogía permite unir a dos grupos de educadores que se encuentran en los extremos de la jerarquía educativa: los maestros de la escuela infantil y los profesores e investigadores universitarios. La consecuencia de esto ha sido la profesionalización y la elevación del status del maestro de pre-escolar y de escuela infantil; un status que no se basa en una competencia específica sino en una identidad educativa débil (sin sujeto). Desde este punto de vista, el status de los maestros se basa en un control simbólico difuso, tácito, el cual está legitimado por una ideología explícita cerrada, esencia de la clasificación y enmarcamientos débiles.

\section{Clase y Pedagogía Invisible}

De nuestra discusión anterior podemos abstraer los siguientes puntos:

1) La pedagogía invisible es un sistema interruptor, tanto en relación con la familia como en relación con otros niveles de la jerarquía educativa.

2) La pedagogía invisible transforma las estructuras sociales y contextos culturales privatizados de la pedagogía visible en una estructura social personalizada y en contextos personalizados.

3) La educación implícita revela una naturaleza única.

La pregunta que surge aquí es: ¿Qué interrumpe la pedagogía invisible? La pedagogía invisible fue primero institucionalizada en el sector privado para una fracción de la clase media, la nueva clase media. Si las ideologías de la vieja clase medía fueron institucionalizadas en las escuelas públicas y a través de éstas en las "grammar schools", asimismo la ideología de la nueva clase media fue primero institucionalizada en los preescolares privados, más tarde, en las escuelas de secundaria públicas y privadas, y, finalmente en el sistema estatal, en el nivel de la escuela infantil. Así, desde este punto de vista, el conflicto entre las pedagogías visibles e invisibles, entre clasificación y enmarcaciones fuertes y débiles, es un conflicto ideológico dentro de la clase media. Las ideologías de la educación son todavía ideologías de clase. La vieja clase media fue domesticada mediante clasificación y enmarcaciones fuertes de la familia y de las escuelas públicas, las cuales intentaron, a menudo de manera exitosa, la reproducción cultural. Pero, ¿qué tipo social fue reproducido?

\footnotetext{
*Las "grammar schools" en Inglaterra eran los colegios de secundaria para la élite. Aún hoy subsisten algunos con el mismo carácter. (N.T.).
} 
Nosotros sabemos que cada sociedad industrializada produce solidaridad orgánica. Ahora bien, Durkheim, —-me parece- - se preocupó sólo por una forma de solidaridad —la forma que creó el individualismo. Durkheim se interesó en las vicisitudes de los tipos hasta donde su clasificación y en-marcaciones no fueron más, o sólo fueron, integradas moralmente de manera débil o cuando las relaciones del individuo con la clasificación y en-marcaciones sufrieran un cambio. El análisis de Durkheim está basado en la vieja clase media. Durkheim no previó - aun cuando sus procedimientos conceptuales lo hacen posible - una forma de solidaridad orgánica basada en una clasificación débil y en enmarcaciones débiles; esto es, una forma de solidaridad desarrollada por la nueva clase media. El concepto de solidaridad orgánica de Durkheim se refiere a los individuos en relaciones de clase privatizadas; la segunda forma de solidaridad orgánica se refiere a personas en relaciones de clase privatizadas ${ }^{31}$. La segunda forma de solidaridad orgánica celebra la aparente liberación, no del individuo sino de las personas, y las nuevas formas de control social ${ }^{32}$. Así pues, podemos distinguir dentro de la clase media formas de solidaridad orgánica individualizada y personalizada, cada una con sus propias ideologías distintivas y opuestas y cada una con sus propias formas distintivas y opuestas de socialización y de realidad simbólica. Estas dos formas de solidaridad surgen de los desarrollos de la división del trabajo dentro de sociedades de clase. La solidaridad orgánica individualizada de Durkheim se desarrolló a partir de la creciente complejidad de la división económica del trabajo; la solidaridad orgánica personalizada, es posible sugerir, surge del incremento en la división social del trabajo de control simbólico o cultural del cual se ha apropiado la nueva clase media. La nueva clase media es un sistema interruptor, no, indudablemente de relaciones de clase sino de la forma de su reproducción. En términos de Bourdieu, ha habido un cambio en el habitus, pero no en la función. Este cambio en el habitus ha tenido amplios efectos sobre la institucionalización selectiva de los códigos educativos y la codificación en las áreas del sexo y de la estética, y sobre las agencias preparadoras y reparadoras, tales como la familia, la escuela, y los hospitales psiquiátricos. En todas estas áreas ha habido un cambio hacia la clasificación y enmarcaciones débiles ${ }^{33}$.

\footnotetext{
${ }^{31}$ Esto significa un cambio de la producción de tipos diferenciados de individuos a la producción de un tipo de persona.

${ }^{32}$ Es asunto de algún interés, el considerar los cambios en el énfasis de las metodologías de investigación durante las últimas décadas. Ha habido un cambio de los cuestionarios cerrados estandarizados y del contexto experimental hacia contextos y relaciones más desestructuradas. Se argumenta que la primera metodología hace irrelevantes los significados subjetivos de aquellos quienes son objeto de estudio. Al hacer esto, el investigado ofrece su experiencia a través de los medios de la fuerte clasificación y fuerte enmarcación impuestas por el investigador. Se argumenta, además, que tal método de estudiar las personas se deriva de un método para el estudio de los objetos y, por lo tanto es un ultraje a la subjetividad del hombre su transformación en objeto. Tales argumentos ligan los métodos positivistas con el control político del hombre mediante el uso de la tecnología de las ciencias sociales. La nueva metodología aparentemente emplea una clasificación y enmarcaciones débiles, pero usa técnicas (observación participante, grabaciones, video-tapes, etc.) que facilitan que más aspectos del investigado se hagan visibles, y que permiten a un número mayor de observadores presenciar la conducta espontánea del observado. Aún, si estos registros públicos de la conducta natural, son tratados como un medio de diálogo entre el que registra y el registrado, este diálogo está, en sí mismo, sujeto a la disyunción entre las perspectivas intelectuales que configuran la comunicación.

El manejo de la comunicación por parte del investigador es diferente del manejo que le da el investigado, y esto constituye el control invisible. Paradójicamente, por otra parte, en el caso del cuestionario cerrado la privacidad del sujeto se mantiene segura, pues lo único que se puede hacer público es la marca de un lápiz, la cual se transforma en un puntaje impersonal. Además, los métodos de esta transformación deben hacerse públicos; de esta manera sus presupuestos pueden ser criticados. En el caso de la nueva metodología, los principios que se usan para restringir la gran cantidad de información y el número de canales son a menudo implícitos. Se puede decir que podríamos distinguir las metodologías de la investigación en términos de la pedagogía que crean: invisible o visible. La pedagogía invisible da origen a una vigilancia total de la persona quien, a diferencia de la persona de la pedagogía visible, hace públicos más aspectos de su interioridad (su subjetividad, por ejemplo), la cual se evalúa mediante el uso de criterios difusos e implícitos. Aquí estamos sugiriendo que los orígenes estructurales de los cambios en la clasificación y enmarcación de las formas de socialización pueden, tal vez, influenciar también la selección de metodologías de la investigación. La moralidad de las relaciones de investigación trasciende los dilemas de un investigador particular. Las metodologías de la investigación en ciencias sociales constituyen en sí mismas, elementos de la cultura.

${ }^{33}$ Es interesante ver, por ejemplo, dónde se ubicó por primera vez la pedagogía invisible dentro del currículum de la escuela secundaria. Podríamos sugerir que en Inglaterra la pedagogía invisible primero penetró al área no verbal de las escuelas secundarias no selectivas; el área que se considera como la menos relevante (en el sentido de que no produce propiedad simbólica) y la más fuertemente clasificada: el área del salón de artes. Se podría decir que hasta hace poco la mayor continuidad simbólica de las pedagogías entre los niveles de primaria y secundaria se encontraba en las áreas no verbales del curriculum.
}

Digitalizado por RED ACADEMICA 
Este conflicto dentro de la clase media se realiza de manera aguda en los diferentes patrones de socialización de los jóvenes. En la vieja clase medía, la socialización se da dentro de una clasificación fuerte y una enmarcación fuerte, donde las fronteras permiten tácitamente la circulación de mensajes condensados críticos. En la nueva clase media, la socialización se da dentro de una clasificación y enmarcación débiles, que promueve mediante la claridad y completa expresión del código de comunicación, una ambigüedad mucho mayor, y que impulsa a esta clase a hacer visible la ideología de su socialización. Para esta ideología es crucial el concepto de persona y no el de individuo. Mientras que el concepto de individuo orienta hacia identidades de roles específicos y sin ambigüedad, y hacia desempeños de roles relativamente inflexibles, el concepto de persona orienta hacia una identidad personal ambigua y a desempeños de roles flexibles. Tanto la vieja como la nueva clase media hacen uso de teorías biológicas, aunque de tipos muy diferentes. La vieja clase media sostenía teorías que generaron tipos biológicamente fijos donde la variedad del tipo constituía una amenaza para la reproducción cultural. La nueva clase media también sostiene teorías que enfatizan un tipo biológicamente fijo, pero también sostiene que dicho tipo está abierto a gran variedad. Esto, en esencia, constituye una teoría que apunta hacia la movilidad social, hacia la meritocracia. Para la vieja clase media, la variedad debe ser reducida severamente con el propósito de asegurar la reproducción cultural; para la nueva clase media, la variedad debe ser estimulada con el propósito de asegurar la interrupción. La reproducción y la interrupción se crean mediante la variación en la fuerza de las clasificaciones y enmarcaciones ${ }^{34}$. A medida que éstas se debilitan, la socialización estimula para que la mayor parte de lo socializado se haga visible, para que su unicidad se haga manifiesta. Tal socialización es profundamente

El salón de artes, es a menudo considerado por el resto del personal docente como un área de relajamiento o, incluso, de terapia, antes que como un espacio de producción fundamental. A causa de su fuerte clasificación e irrelevancia (excepto en los períodos de demostración de la escuela) este espacio está potencialmente abierto al cambio. Los maestros de arte son entrenados en instituciones (al menos recientemente) que son muy sensibles a la innovación, y por lo tanto es probable que nuevos estilos se institucionalicen rápidamente en las escuelas, dada la fuerte clasificación del arte en el currículum de la escuela secundaria, y también dada la creencia de que los niños menos capaces pueden al menos hacer algo con sus manos aun si éstos encuentran dificultad con el lápiz. Podríamos también anticipar que con el interés en las formas musicales como el Pop por una parte y Cage y Stockhausen, por la otra, la música probablemente se mueva hacia la pedagogía invisible. Para completar la dirección en el área verbal, es posible que la transformación del entrenamiento físico en educación física puede también hacer parte de este movimiento. Si este desarrollo tiene lugar, entonces las áreas no verbales podrían manifestarse mediante la pedagogía invisible. Nosotros podemos esperar entonces una orientación hacia la integración de tres áreas, el área visual, el área acústica, y el área del movimiento; tres áreas que estarían entonces ligadas mediante un código común.

${ }^{34}$ Los problemas planteados en el presente artículo pueden clarificarse en la siguiente forma: Todo contexto de socialización debe estar compuesto de un transmisor y de un adquiriente, (receptor). Transmisor y adquiriente forman una matriz en el sentido que la comunicación está regulada por un principio estructural. Hemos sugerido que el principio subyacente de una matriz socializante se manifiesta en la clasificación y enmarcaciones. La relación entre las dos y las fuerzas respectivas nos muestra la estructura del control y la forma de la comunicación. Nosotros podemos, por supuesto, analizar esta matriz en cierto número de formas: (1) podemos centramos en el transmisor; (2) podemos centrarnos en el adquiriente; (3) podemos centrarnos en los principios que subyacen a la matriz; (4) podemos centrarnos sobre una matriz dada e ignorar su relación con otras matrices; (5) podemos considerar las relaciones entre matrices críticas, esto es, la familia, los grupos de amigos de la misma edad, la escuela, el trabajo.

Podemos continuar preguntándonos acerca de la función de una matriz y acerca del cambio en la forma de su manifestación, esto es, cambios en la fuerza de su clasificación y enmarcación, Nosotros creemos que la unidad de análisis debe ser siempre la matriz y ésta deberá incluir siempre las teorías y métodos de su análisis, (véase nota 4 sobre metodología de la investigación). Ahora bien, cualquier matriz puede mirarse como una matriz reproductora. interruptora, o de cambio, Una matriz reproductora intentará crear una clasificación fuerte y una en-marcación fuerte. Una matriz interruptora cambia la forma de la transmisión pero no las relaciones críticas entre las matrices. Una matriz de cambio conduce a un cambio fundamental en la relación estructural entre matrices. Esto requeriría un gran cambio en la estructura institucional. Por ejemplo, hemos argumentado que dentro de la clase media existe un conflicto que ha generado dos matrices socializantes diferentes, la una reproductora y la otra interruptora. Y estas matrices trabajan, dentro de la otra educación, para grupos distintos de alumnos en la escuela secundaria. Sin embargo, debido al hecho que la relación estructural entre la escuela y el trabajo no se ha cambiado (esto es, no ha habido un cambio básico en los principios de su relación), no podemos mediante este argumento ver las diferencias corrientes en la pedagogía educativa como representantes de una matriz de cambio. En otras palabras, la forma de la reproducción de las relaciones de clase en educación ha sido interrumpida pero no cambiada. Podemos, entonces, especular que el conflicto ideológico dentro de la clase media toma la forma de un conflicto entre los resultados simbólicos de las matrices de reproducción e interrupción. Si uno avanza un poco más en la argumentación debe considerar la reproducción del cambio en la forma de las relaciones de clase. En este caso la reproducción de una matriz interruptora se realiza mediante clasificación y enmarcación débiles. Sin embargo, es posible que tal forma de reproducción puede en cierto momento, evocar su propia forma de interrupción, esto es, un incremento bien sea en la clasificación, bien sea en la enmarcación, o bien sea en ambas. 
penetrante y mucho más completa a medida que la vigilancia se hace más invisible. Esta es la base del control que crea la solidaridad orgánica personalizada. Así, las formas de socialización dentro de las dos fracciones opuestas de la clase media constituyen los orígenes de las pedagogías visibles e invisibles en la escuela. Tenemos aquí una semejanza entre la interrupción por parte de la nueva clase media de la reproducción de la nueva clase y de la interrupción por parte de la nueva pedagogía educativa de la reproducción de la vieja pedagogía; una semejanza entre el conflicto en la clase media y el conflicto entre dos pedagogías: sin embargo, este es un conflicto entre la interrupción de las formas de transmisión de las relaciones de clase. Desarrollaremos, ahora, este punto. La nueva clase media, como la proponente de la pedagogía invisible, está atrapada en una contradicción, pues sus teorías están en oposición con sus relaciones objetivas de clase. El carácter de este grupo es de una ambivalencia profundamente arraigada. Por una parte, defiende la variedad, contra la inflexibilidad, la expresión, contra la represión, lo interpersonal, contra la interposicional. Por otra parte, existe el inflexible mantenimiento de la división del trabajo y el estrecho acceso a sus posiciones de poder y prestigio. Bajo la solidaridad orgánica individualizada, la propiedad tiene una naturaleza esencialmente física; sin embargo, con el desarrollo de la solidaridad orgánica personalizada, a pesar de que la propiedad en el sentido físico no pierde su importancia, esta ha sido parcialmente psicologizada y se presenta en la forma de propiedad de habilidades de gran valor suministradas por las instituciones educativas. Así, si la nueva clase media debe reproducir su posición en la estructura de clase, entonces la socialización secundaria apropiada dentro de la educación privilegiada se hace crucial. Pero a medida que la relación entre educación y ocupación se hace más directa y más estrecha en el tiempo, las clasificaciones y las enmarcaciones aumentan su fuerza. De esta manera, la nueva clase media mantiene cierto entusiasmo ambivalente por la pedagogía invisible para la socialización temprana del niño, pero acepta la pedagogía visible para la escuela secundaria; y continuará haciendo esto hasta cuando la universidad se oriente hacia una clasificación y una enmarcación más débiles de sus principios de transmisión y selección. Por otra parte, la nueva clase media se encuentra entre los líderes del movimiento para institucionalizar la pedagogía invisible en las instituciones pre-escolares del estado y a menudo para su penetración en la escuela primaria y su extensión posterior a la escuela secundaria. $Y$ esto puede realizarse con confianza ya que la escuela secundaria puede suministrar, probablemente, tanto las pedagogías visibles como las invisibles; la primera para la clase medía y la segunda para la clase obrera.

\section{Control Simbólico ${ }^{35}$ y la Identificación de la Nueva Clase Media}

Cualquiera que sea la forma como se define una clase dominante, ésta tiene una relativa relación directa con los medios y formas de producción y una relativa relación indirecta con los medios y formas de reproducción cultural. Son los diversos estratos de la clase medía los que tienen una relación directa con los medios y formas de reproducción cultural, pero sólo una relación indirecta con los medios y formas de producción. Lo que aquí llamamos la vieja clase media (esencialmente la del siglo XIX) está basada en la ideología del individualismo radical (una forma de integración que puede caracterizarse como solidaridad orgánica individualizada) ya fueran sus funciones empresariales 0 profesionales. La ideología del individualismo radical presupone valores explícitos y sin ambigüedad. Es esta claridad en los valores lo que es fundamental para la transmisión y reproducción de las pedagogías visibles. Las jerarquías explícitas de las pedagogías

\footnotetext{
${ }^{35}$ Control simbólico es el medio de reproducción cultural, en términos de Bourdieu. Lo que se reproduce es una función del grado de integración dentro de, o del conflicto entre los agentes de transmisión y la respuesta de aquellos que están sujetos a la transmisión. Lo que debe ser explorado son las complejas relaciones entre los cambios en las formas de producción y los cambios en las formas de control simbólico.
} 
visibles requiere una legitimación basada en valores explícitos y sin ambigüedad. La nueva clase media, como una estructura, es una formación que surge a partir de la primera mitad del siglo $\mathrm{XX}$ de la organización científica del trabajo y del capitalismo corporativo. La nueva clase media es tanto un producto como un soporte de la expansión articulada de la educación y los campos de control simbólico. Ella está ambiguamente localizada en la estructura de clase. La ambigüedad de su ubicación se relaciona probablemente con la ambigüedad en sus valores y propósitos. Tal ambigüedad cambia la modalidad de control simbólico. Las pedagogías invisibles descansan sobre jerarquías implícitas que no requieren legitimación mediante valores explícitos y sin ambigüedad La forma de integración de esta fracción se orienta hacia la solidaridad orgánica personalizada. Esta fracción de la clase media puede ser considerada como los diseminadores de nuevas formas de control social. La oposición entre fracciones de la clase media no es una oposición acerca del cambio radical en la estructura de clase, sino una oposición basada en formas opuestas de control social.

A continuación ofreceremos una clasificación de las agencias y agentes de control simbólico:

1) Reguladores: Miembros del sistema legal, la política, el servicio de prisiones, la Iglesia.

2) Reparadores: Miembros del servicio médico y psiquiátrico y sus derivaciones; los servicios sociales.

3) Difusores: Maestros en todos los niveles y áreas. Los medios de comunicación masiva y medios especializados.

4) Modeladores: Los creadores de lo que cuenta como desarrollo en, o cambio de, las formas simbólicas en las artes y las ciencias.

5) Ejecutores: El servicio civil y la burocracia.

Mientras es verdad que la categoría (1) —Reguladores - bien puede ser clasificada como mantenedores, queremos enfatizar que éstos juegan un papel legal importante en la regulación del flujo de personas, actos, ideas. En la misma forma, algunos reparadores muy probablemente tienen más funciones de reguladores (en el sentido anotado anteriormente) que de reparadores. Además, cada categoría tiene tanto su propia jerarquía como sus propios conflictos ideológicos internos. De la misma manera probablemente existan conflictos ideológicos entre las categorías que unen a agentes que ocupan posiciones similares o disimilares en las jerarquías respectivas. Mientras que podemos distinguir la estructura de integración, de control social y los procesos de transmisión que caracterizan a la nueva clase media, observamos que los agentes se encuentran en proporciones diferentes en los diferentes niveles de la jerarquía en cada categoría. Esto es un problema de continua investigación. Es igualmente asunto de importancia (siguiendo a Bourdieu) considerar la estructura subyacente del campo de reproducción cultural, constituido por los agentes y las agencias de control simbólico, la estructura subyacente de las inter-relaciones de los agentes y' agencias y las formas de control simbólico. Los agentes pueden ser clasificados fuerte o débilmente en términos de la extensión de sus actividades en más de una categoría, y ellos pueden emplear procedimientos de enmarcación fuertes o débiles. El análisis de la clasificación y enmarcación puede aplicarse dentro de una categoría, o entre categorías. El análisis en este artículo está centrado en los cambios en la forma de transmisión.

Breve discusión de la clasificación 
1) Reguladores: Estos constituyen las agencias y los agentes cuya función es definir, supervisar y mantener los límites de personas y actividades. ¿Por qué colocar las agencias religiosas oficiales dentro de los regulares? Estas agencias en un tiempo informaron y legitimaron los rasgos del sistema legal. Hoy, la relación entre las agencias religiosas oficiales y el sistema legal es más compleja. El papel de las agencias religiosas oficiales como reguladores morales ha sido considerablemente debilitado, aunque, en ciertas sociedades, las agencias religiosas oficiales han jugado un papel activo en el apoyo a aquellos quienes aspiran a cambiar el sistema (por ejemplo, la Iglesia Católica Romana en América Latina). Las agencias religiosas oficiales han sido agrupadas con la estructura de las agencias legales a causa de su función como agencias reguladoras de control simbólico.

2) Reparadores: Estos conforman las agencias cuya función consiste en prevenir, reparar o aislar, lo que centa como traumas en el cuerpo, la mente y las relaciones sociales. Como lo hemos mencionado anteriormente, en diferentes épocas y en diferentes sociedades, algunos reparadores pueden actuar como reguladores; en otras ocasiones los subgrupos bien pueden estar en conflicto con los reguladores.

3) Difusores: Estos conforman las agencias y los agentes cuya función consiste en diseminar ciertos principios, prácticas, actividades y formas simbólicas, o apropiar principios, prácticas y formas simbólicas con el propósito de inducir el consumo de formas simbólicas, bienes materiales, servicios o actividades.

4) Modeladores: Estos conforman las agencias y los agentes cuya función es desarrollar lo que cuenta como el cambio de códigos simbólicos fundamentales, en las artes o en las ciencias. El problema aquí consiste en que en ciertos niveles existe un entrecruzamiento con los difusores. Podríamos argumentar que los productores de cine, los propietarios de galerías y de teatros, y los publicistas, constituyen un importante subconjunto de difusores, sobre el presupuesto de que ellos operan medios especializados. Sin embargo, ¿qué podemos hacer con los artistas (actores, músicos, bailarines) y críticos especializados? Pienso que podríamos argumentar que los artistas deberían ser clasificados como difusores y los críticos especializados como modeladores.

5) Ejecutores: Estos conforman las agencias y los agentes cuya función es administrativa. Las agencias más importantes aquí son el servicio civil y el gobierno local, aunque es importante señalar que los ejecutores existen como agentes en las agencias mencionadas anteriormente.

Hemos dejado por fuera toda el área de los deportes, la cual, es indudablemente, una agencia fundamental en el sentido estricto por la siguiente razón: la clasificación ha sido establecida con el fin de examinar los cambios en las formas de control simbólico, punto decisivo para el análisis del problema de las relaciones entre reproducción de clase y reproducción cultural. Desde este punto de vista, y sólo desde este punto de vista, el deporte no constituye una agencia fundamental.

Presupuestos de clase de las pedagogías invisibles: La mujer como agente de reproducción cultural en la clase media.

El cambio de la solidaridad orgánica individualizada a la solidaridad orgánica personalizada en la clase media cambia la estructura de las relaciones sociales en la familia y, en particular, el papel de la mujer en la socialización del niño. Históricamente, 
bajo la solidaridad orgánica individualizada, la madre no juega un papel importante como transmisora tanto de la propiedad simbólica como de la propiedad física. Ella está casi totalmente abstraída de los medios de reproducción tanto de la propiedad física como de la simbólica. El cuidado y la preparación de los niños es delegado a otros agentes niñera, institutriz, tutor- La madre es esencialmente una administradora doméstica y en consecuencia sólo puede ser un modelo para su hija. La mujer estaba capacitada para la reproducción cultural, pues a menudo poseía un mayor conocimiento y una mayor comprensión que su esposo de la literatura general del período. Este concepto de la función maternal abstracta reaparece, tal vez, en el concepto de la asistente pre-escolar como una cuidadora de niños, y de la institutriz como la maestra de las competencias elementales. De esta manera, la solidaridad orgánica individualizada pudo generar dos modelos femeninos para la educación formal temprana del niño.

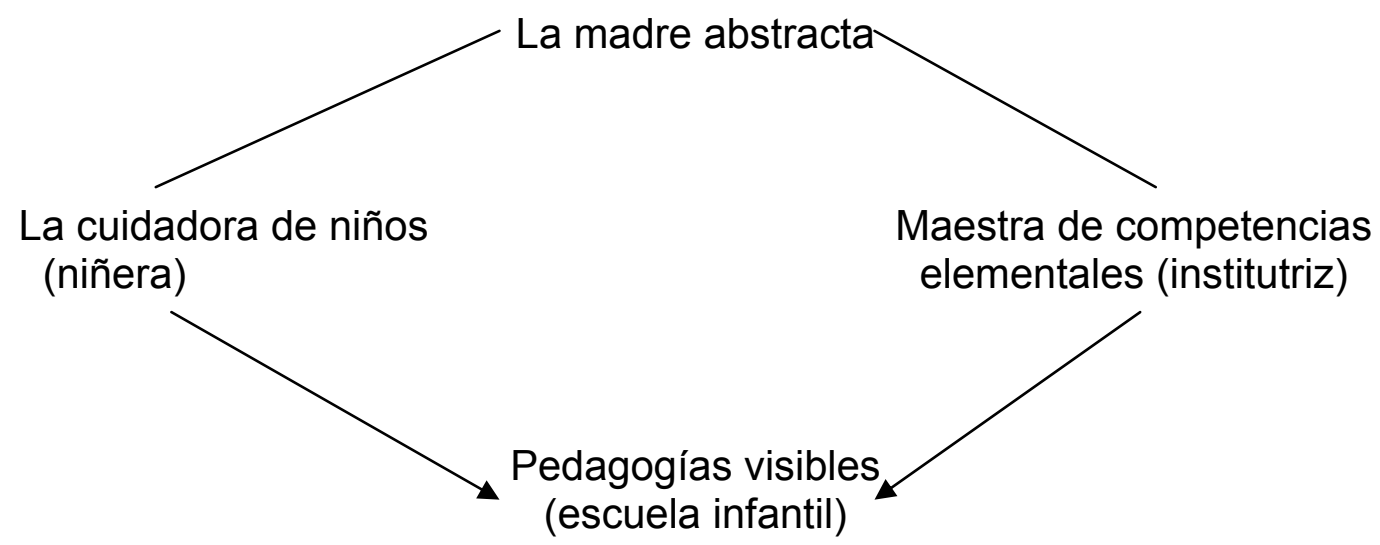

Inicialmente, con la solidaridad orgánica individualizada, la propiedad tiene una base física, que existe en formas de capital y donde la posesión y control están combinados. Aquí, el acceso a, y la reproducción de, la posición de clase están relacionados con el acceso al, y propiedad del, capital. A pesar de que existe, claramente, un nexo entre clase y formas de educación, la educación en sí misma juega un papel relativamente escaso en la creación del acceso a, y la reproducción de, la posición de clase. Sin embargo, en las formas desarrolladas del capitalismo las funciones de manejo no sólo se divorcian de la propiedad, sino que también hay una expansión de las posiciones de control social que tienen sus bases en formas especializadas de comunicación, las cuales están cada vez más al servicio del sistema educativo. Con esta extensión y diferenciación de las funciones de control, la base de la propiedad se psicologiza parcialmente y se localiza en la posesión de formas especializadas de comunicación. Estas, a su vez tienen su origen en formas de interacción especializadas, iniciadas, desarrolladas y centradas muy temprano en la vida del niño. El papel de la madre en la crianza del niño sufre un cambio cualitativo. La madre se transforma en un agente preparador fundamental de reproducción cultural que proporciona el acceso a formas simbólicas y configura las disposiciones de sus niños para que éstos sean más capaces de explotar las posibilidades de la educación pública. Nosotros podemos ver una integración de las funciones maternas en la medida en que las bases de la posición de clase se psicologizan. La preparación y el cuidado maternal delegados se transforman en cuidado y preparación maternal. Lo que interesa aquí es la forma del cuidado y la forma de la preparación. De acuerdo con la tesis presentada, la forma puede estar constituida tanto por la pedagogía visible como por la invisible. La vieja clase media se perpetuaba a sí misma mediante una pedagogía visible, mientras que la nueva clase medía, como portadora de las estructuras de la solidaridad orgánica personalizada, desarrolló las pedagogías invisibles. 
La mujer jugó un papel activo en la iniciación (Montessori), configuración y diseminación de las pedagogías invisibles. Consideremos:

1) La aplicación de la teoría Freudiana por Ana Freud al análisis del niño. La modificación de la teoría Freudiana por Melanie Klein y sus seguidoras, Hannah Segal, Joan Riviere y Marion Milner, y el desarrollo de la interpretación del juego como un contenido de fantasía en el análisis del niño.

2) La extensión de la teoría psicoanalítica a la educación y a la formación de docentes (post 1945) a través de Susan Isaacs en el Instituto de Educación de la Universidad de Londres y sus desarrollos posteriores por Dolly Garner. Un trabajo paralelo con una base Piagetiana fue llevado a cabo por Molly Brierley, Directora del "Froebel College of Education".

3) Un gran número de mujeres en un período muy anterior fueron activas en la educación y en la formación de docentes, como por ejemplo, Philippa Fawcett, y Rachel McMillan.

Es posible pensar que las mujeres fueron agentes fundamentales en el último cuarto (y quizás mucho antes) del siglo XIX. Pues debido a que el concepto de niño cambió, también cambié la jerarquía a la cual la mujer estaba subordinada. Al mismo tiempo, la pedagogía proporcionó las bases de una identidad profesional. Desde este punto de vista la mujer transformó el cuidado maternal y la preparación en una actividad científica.

Con el cambio de la solidaridad orgánica individualizada a la solidaridad orgánica personalizada dentro de las fracciones de la clase media la mujer se transforma en un agente preparador fundamental de reproducción cultural. Existe, sin embargo, una contradicción en sus relaciones estructurales. A diferencia de la madre en un contexto de solidaridad orgánica individualizada (pedagogía visible) aquella es incapaz de separarse del niño. La clasificación y enmarcación débiles de la crianza del niño lo aferran firmemente a éste (Véase (3) más adelante). Para tal madre la interacción y la vigilancia demandan mucha atención, mientras, al mismo tiempo, su propia socialización tanto en una identidad personal como ocupacional la alejan de la familia. Estas tensiones pueden ser resueltas parcialmente colocando al niño tempranamente en un pre-escolar, el cual, reproduce fielmente el ambiente de su propia crianza. La escuela infantil, sin embargo, puede amplificar los mensajes y pretende extenderlos hasta la escuela Junior *. Aquí podemos ver una segunda contradicción, pues tal amplificación conduce a un conflicto entre la escuela y la madre de clase media. El sistema de exámenes públicos se basa en una pedagogía visible que se realiza a través de una clasificación fuerte y de una enmarcación relativamente fuerte. Es esta pedagogía la que genera la propiedad simbólica, esto es, los medios por los cuales la posición de clase se reproduce. Si el acceso a la pedagogía visible se retarda demasiado, entonces, el éxito en los exámenes puede ponerse en peligro.

Aquí se ha desarrollo el argumento de que una pedagogía invisible se basa en un concepto de la mujer como agente preparador particular de reproducción cultural —un agente que tiene sus orígenes en una fracción de la clase media.

Tornaremos ahora al análisis de los presupuestos de clase más específicos de la pedagogía invisible.

\section{El Concepto de tiempo}

\footnotetext{
* La escuela junior se puede asimilar al ciclo básico de la escuela secundaria. (N.T.) 
En primer lugar, las pedagogías invisibles se basan en un concepto de tiempo de clase media porque éstas presuponen una larga vida educativa. Sí todos los niños dejaran la escuela a los catorce años no existirían las pedagogías visibles. Las pedagogías visibles están reguladas por reglas de secuencia explícitas, esto es, el progreso de la transmisión está ordenado en el tiempo por reglas explícitas. En la escuela, el syllabus regula el progreso de una materia y el curriculum regula las relaciones entre las materias y aquellas seleccionadas como apropiadas para una edad dada. Las reglas de secuencia, cuando son explícitas, definen los estados de conciencia y comportamiento que se esperan del niño en un futuro. Sin embargo, en el caso de las pedagogías invisibles, las reglas de secuencia no son explícitas, sino implícitas. El progreso de la transmisión se basa en teorías sobre el desarrollo interior del niño (cognitivo, moral, emocional, etc.). Las reglas de secuencia se derivan de teorías particulares sobre el desarrollo del niño. En el caso de las pedagogías invisibles es totalmente imposible para el niño saber, o ser consciente, de los principios de su progreso. El niño o la niña no pueden conocer los principios de su propio desarrollo tal como están expresados en las teorías reguladoras. Sólo el transmisor conoce los principios, esto es, las reglas de secuencia. Las reglas de secuencia en lugar de ser explícitas están implícitas en la transmisión. Podemos generalizar y decir que las reglas de secuencia de una transmisión definen su dimensión temporal. Sin embargo, dichas reglas hacen algo más que esto. Debido a que ellas regulan los estados de conciencia y comportamiento que se esperan en un futuro, las reglas de secuencia definen lo que se espera que el niño sea en diferentes momentos del tiempo, en cuyo caso ellas definen el concepto de niño. De aquí se deduce que debido a que las pedagogías visibles e invisibles son reguladas por reglas de secuencia diferentes, y desde cierto punto de vista, opuestas, ellas presuponen conceptos de tiempo diferentes y se basan en conceptos de niño diferentes. Las pedagogías visibles e invisibles se basan en conceptos diferentes de infancia y en su transformación progresiva, que tiene sus orígenes en diferentes fracciones de la clase media.

\section{Concepto de espacio}

En primer lugar, las pedagogías invisibles requieren para su transmisión una estructura material diferente de la estructura material sobre la cual se basa la pedagogía visible. Una pedagogía visible requiere únicamente un espacio fijo muy pequeño; esencialmente una mesa, un libro y una silla. Su estructura material es extremadamente barata. Sin embargo, con el fin de que su base material sea explotada dicha pedagogía requiere, aún, una forma de adquisición regulada por un código elaborado. Sin embargo, en el caso de la pedagogía invisible, su base material es una superficie mucho más grande. Considérese las grandes hojas de papel, la necesidad de espacio que demanda su tecnología, los bloques y materiales para desarrollar la creatividad, esto es, un conjunto de medios a través de los cuales puede únicamente revelarse la conciencia del niño. La tecnología requiere un espacio relativamente más grande para el niño. En este sentido la producción de una pedagogía invisible en el hogar no puede efectuarse cuando su espacio está sobrehabitado y es materialmente inadecuado. Así, pues, las pedagogías- invisibles se basan en un concepto de espacio mucho más fundamental. Las pedagogías visibles se realizan a través de un espacio fuertemente clasificado, esto es, existen fronteras muy fuertes entre un espacio y otro y el control de los espacios está, igualmente, fuertemente clasificado. Los cuartos en la casa tienen funciones especializadas; la organización de las sillas, por ejemplo, en las comidas está especificada de acuerdo con la clasificación de las personas: madre, padre, hijos; existen fronteras explícitas y fuertemente marcadas que regulan el movimiento de personas en el espacio, en tiempos diferentes. Además, los contenidos de los diferentes espacios no son intercambiables, esto es, los espacios para comer son espacios para comer, las áreas de los niños y sus contenidos son las áreas de 
los niños y sus contenidos, la cocina es la cocina, etc. La jerarquía explícita de la pedagogía visible crea espacios y relaciones entre espacios que llevan un conjunto específico de mensajes simbólicos los cuales ilustran el principio de que las cosas deben mantenerse separadas.

Sin embargo, en el caso de las pedagogías invisibles, el espacio tiene una significación simbólica diferente, pues aquí los espacios y sus contenidos están, relativamente, débilmente clasificados. Los controles sobre el flujo de personas y objetos entre los espacios son mucho más débiles. Esto significa que el espacio potencialmente disponible para el niño es mucho mayor. La privacidad que el espacio regulado por las pedagogías visibles incorpora se reduce considerablemente. Los arquitectos tienden a llamar la organización espacial de las pedagogías invisibles "open-plan living". El niño aprende a comprender las posibilidades de estos espacios débilmente clasificados y las reglas sobre las cuales se fundamenta su aprendizaje. Podemos indicar, de paso, la ironía de una pedagogía invisible, por una parte; y por la otra, el hecho de la visibilidad continua de las personas y sus conductas, esto es, la posibilidad de una vigilancia continua. Las pedagogías invisibles se fundamentan en conceptos derivados de una fracción de la clase media.

\section{El Concepto de control social}

Donde la pedagogía es visible, la jerarquía es visible, el espacio y el tiempo están regulados por principios explícitos y existen límites fuertes entre los espacios, tiempos, actos y comunicaciones. El poder expresado mediante la jerarquía mantiene las fuertes delimitaciones y la separación de las cosas. Una vez el niño aprende estas reglas, adquiere la clasificación. Una violación de la clasificación se hace inmediatamente visible, pues cualquier infracción señala que algo está fuera de lugar, ya sea la comunicación, un acto, una persona o un objeto. La tarea consiste en conseguir que el niño acepte (no necesariamente que entienda) los principios ordenadores. Esto puede realizarse (no necesariamente siempre) ligando las infracciones a un cálculo explícito del castigo y a anuncios relativamente simples de las reglas que prescriben y que proscriben. La motivación se incrementa por medio de una ampliación gradual de los privilegios en relación con la edad. La jerarquía se hace manifiesta en las clasificaciones, en las fuertes delimitaciones dentro de los aislamientos. El lenguaje del con-control social es relativamente restringido y las relaciones de control son explícitamente jerárquicas.

Sin embargo, donde la pedagogía es invisible, la jerarquía es implícita y el espacio y el tiempo están débilmente clasificados. Esta estructura social no crea en sus arreglos simbólicos delimitaciones fuertes que conlleven mensajes de control severos. A causa de que la jerarquía es implícita (lo cual no significa que ésta no esté presente sino que la forma de su manifestación es diferente) existe una relativa ausencia de regulaciones fuertemente marcadas de los actos del niño, de la comunicación, de los objetos, los espacios, de los tiempos y del progreso. ¿En qué descansa el control? Sugerimos que el control es inherente a la comunicación interpersonal elaborada en un contexto donde es posible la máxima vigilancia. En otras palabras, el control está encubierto en el proceso de comunicación interpersonal. La función particular del lenguaje es de especial significación, y su manifestación es la de una forma elaborada en contraste con una forma de comunicación más restringida donde la pedagogía es visible. La forma de transmisión de una pedagogía invisible estimula a que más aspectos del niño se hagan públicos y de esta manera susceptibles de un control y vigilancia directos o indirectos. Así, las pedagogías invisibles presentan modalidades específicas de control social que tienen sus orígenes en una fracción particular de la clase media. 
Hemos intentado hacer explícitos 4 presupuestos de clase que subyacen a la transmisión de una pedagogía invisible.

1) La pedagogía invisible presupone un concepto particular de la madre como un agente preparador fundamental de reproducción cultural.

2) La pedagogía invisible presupone un concepto particular del tiempo.

3) La pedagogía invisible presupone un concepto particular del espacio.

4) La pedagogía invisible presupone una forma particular de control social, la cual es inherente a la comunicación interpersonal (Código elaborado, centrado en la persona).

Las consecuencias educativas de una pedagogía invisible, serán, según esta tesis, fundamentalmente diferentes, dependiendo de la posición social de clase del niño.

Comenzamos esta sección abstrayendo los siguientes puntos de nuestra discusión inicial sobre la pedagogía invisible.

1) La pedagogía invisible es un sistema interruptor, tanto en relación con la familia como en relación con otros niveles de la jerarquía educativa.

2) Ella transforma las estructuras sociales y contenidos culturales privatizados de la pedagogía visible en una estructura social personalizada y en contenidos culturales personalizados.

3) La pedagogía invisible cree que una educación implícita revela una naturaleza única.

Nosotros hemos argumentado que esta pedagogía es una de las manifestaciones del conflicto entre la vieja y la nueva clase media, el cual, a su vez, tiene sus bases sociales en las dos formas diferentes de solidaridad orgánica, individualizada y personalizada. Hemos considerado que estas dos formas de solidaridad surgen de las diferencias en relación con, y de la expansión de, la división del trabajo dentro de la clase medía; que el movimiento de solidaridad individualizada a solidaridad personalizada interrumpe la forma de la reproducción de las relaciones de clase; que tal interrupción da origen a diferentes formas de socialización primaria dentro de la clase media; que la forma de la socialización primaria dentro de la clase media es el modelo para la socialización primaria en la escuela; que existen contradicciones dentro de la solidaridad orgánica personalizada las cuales crean ambigüedades profundamente sentidas, y como consecuencia, los resultados de la forma de socialización son menos seguros. La nueva clase media contemporánea es única, pues en la socialización de sus jóvenes existe una aguda y penetrante contradicción entre una identidad personal subjetiva y una identidad privatizada objetiva, una contradicción entre la liberación de la persona y la jerarquía de clase. Lo anterior puede ser representado en la siguiente figura:

Mientras sea posible para la escuela y la universidad cambiar la base de su solidaridad de individualista a personalizada, esto es, relajar su clasificación y enmarcaciones, es más difícil para aquellas agencias cambiar su función privatizante, es decir, la creación del conocimiento como propiedad privada. De ninguna manera se deduce de aquí que el cambio a solidaridad orgánica personalizada cambiará la función privatizante. En efecto, es más probable que el cambio en esta forma de solidaridad ocurra en aquella parte del sistema educativo que no crea propiedad privada, como en el caso de la educación de la 
clase obrera baja, o en la educación de los más jóvenes. Podemos concluir diciendo que los mayores efectos de este cambio en solidaridad se tendrán en las áreas de comunicación condensada (sexo, arte, estilo) y en la forma de control social (de explícito a implícito).

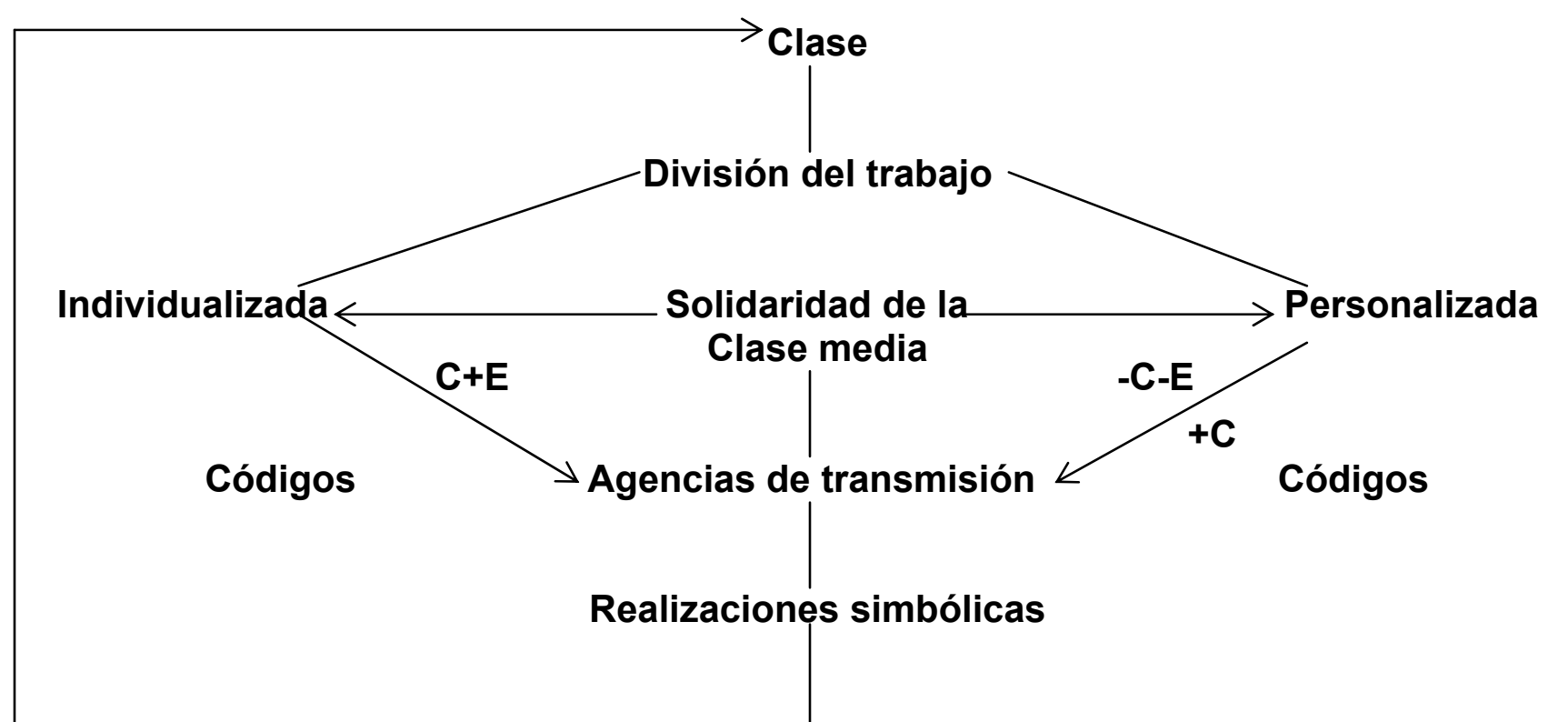

\section{Estructuras mentales}

\section{Transición a la escuela}

\section{Cultura de Clase, Poder y Conflicto}

El cambio de las pedagogías visibles e invisibles en los niveles de educación preescolar y primaria cambia las relaciones entre la familia y la escuela. Ya hemos notado la actitud ambigua de la clase media hacia dicho cambio. En el caso de la clase obrera, el cambio es más radical. La clasificación débil y la enmarcación débil de la pedagogía invisible potencialmente hace posible la inclusión de la cultura de la familia y de la comunidad. De esta manera, la experiencia del niño y su mundo cotidiano podrían ser psicológicamente activos en el salón de clase, y si éste fuera el caso, entonces la escuela más bien legitimaría la cultura de clase de la familia en lugar de rechazarla. Debido a que el ritmo de la transmisión del conocimiento se relaja y el énfasis en el logro temprano de competencias específicas se reduce, el progreso está menos marcado por presupuestos de la clase media. En el caso de las pedagogías visibles la lectura temprana y, especialmente, la escritura son esenciales. Una vez el niño puede leer y escribir se libera del maestro; y más importante aún, una vez el niño puede leer se le puede dar un libro y una vez se le ha dado el libro, él está en capacidad de asumir el papel de la relación educativa solitaria y privatizada. El libro es la preparación para recibir el pasado manifiesto en los textos. Y el libro, a su vez, transmite tácitamente la ideología del código agregado, pues éste compendia la clasificación fuerte y las enmarcaciones fuertes. El texto ordena el conocimiento de acuerdo con un progreso explícito, provee criterios explícitos, remueve dudas y anuncia jerarquías. El texto da al niño un índice inmediato de su progreso en relación con otros niños; por lo tanto constituye un medio silencioso de creación de relaciones competitivas. De esta manera, la socialización dentro del texto es un paso fundamental hacia la socialización dentro del código agregado. Entre más fuerte sea el código agregado, esto es, entre más fuerte sean la clasificación y las enmarcaciones, más fuerte será el énfasis en la lectura y escritura temprana. El niño de la 
clase media está preparado para este énfasis, sin embargo, no es éste el caso del niño de clase obrera. El debilitamiento de la clasificación y de la enmarcación reduce la importancia del texto y transforma el pasado impersonal en un presente personalizado. Parecería que la pedagogía invisible conllevará un beneficio potencial para los niños de clase obrera. Sin embargo, debido a que esta pedagogía tiene sus orígenes en una fracción de la clase media, dicha potencialidad probablemente no se manifiesta.

Desarrollaremos este punto a continuación. Desde el punto de vista de los padres de clase obrera, la pedagogía visible del código agregado en el nivel primario es inmediatamente comprensible. Las competencias básicas que esta pedagogía transmite en lectura, escritura y cálculo, en una secuencia ordenada explícita, tiene sentido. Las fallas de los niños son fallas de los niños y no fallas de la escuela, pues la escuela, aparentemente, está cumpliendo su función de manera impersonal. La forma de control social de la escuela no interfiere el control social que ejerce la familia. El maestro de escuela infantil no necesita tener un alto status, pues las competencias que éste transmite pueden, en principio, ser transmitidas por la madre. En este sentido, existe una continuidad (o más bien extensión) simbólica entre la familia de clase obrera y la escuela. Sin embargo, en el caso de la pedagogía invisible posiblemente existe una marcada discontinuidad. Las competencias y su progreso desaparecen y la forma de control social puede variar con respecto a la de la familia. La teoría de la pedagogía invisible puede no ser conocida por la madre o puede que ésta la entienda de manera imperfecta. La falta de énfasis sobre las competencias pueden hacer del niño un miembro menos efectivo (útil) de la familia. Sin embargo, existe una fuente de tensión mucho más importante. La pedagogía invisible contiene una teoría de transmisión diferente y una tecnología nueva que considera la enseñanza informal de la madre allí donde ésta ocurre, o los valores pedagógicos de la madre, como algo irrelevante cuando no completamente dañino. Hay nuevos esquemas de lectura, las matemáticas nuevas remplazan la aritmética, y un estilo estético expresivo remplaza a aquél basado en la copia exacta del modelo. Si la madre quiere ser útil debe ser resocializada o mantenerse aislada del proceso. En ambos casos, las relaciones de poder entre la escuela y la familia han cambiado, pues el maestro tiene el poder y la madre se convierte en un alumno más. Esto a su vez puede alterar las relaciones de autoridad en el hogar, alteración que, además, se facilita mediante el uso de formas implícitas de control social de la escuela. Aunque la pedagogía derive sus contenidos de la cultura de clase, persisten formas básicas de discontinuidad. Si la madre desea comprender la teoría de la pedagogía invisible puede llegar a encontrarse a merced de las complejas teorías del desarrollo infantil. Es claro que, cualquiera sea el camino que la madre de clase obrera tome, es el maestro quien tiene el poder, así, la madre sospeche profundamente del ambiente total de la pedagogía invisible ${ }^{36}$.

Mientras que en el caso de la pedagogía visible, existen para la clase obrera, en relación con la clase media, formas implícitas de discontinuidad y formas explícitas de desigualdad en la configuración del poder que la escuela tiene sobre los maestros, sobre el tamaño de la clase y sobre las formas posibles de agrupamiento de los niños*, en el caso de la pedagogía invisible existe también una discontinuidad simbólica que bien puede coexistir con las desigualdades en la provisión y calidad del personal docente. El maestro también tiene dificultades porque la pedagogía invisible presupone una forma particular de socialización primaria maternal, un pequeño número de alumnos y una arquitectura particular. Cuando estos aspectos están ausentes el maestro puede llegar a

\footnotetext{
${ }^{36}$ Esto no significa que todos los maestros deseen tener poder o usarlo.

*El término en inglés es "streaming" el cual significa que niños de la misma edad son puestos en grupos diferentes de acuerdo con el nivel de sus habilidades generales. Esto es, que los más inteligentes se agrupan en una clase, aquellos de habilidad mediana en otra y los menos Inteligentes en otra clase. (N.T.).
} 
encontrarse con grandes dificultades. De manera ideal, la pedagogía invisible libera al maestro en tal forma que éste tiene tiempo disponible para disminuir las dificultades de cualquier niño. Pero si la clase es grande, la socialización de la escuela inadecuada y la arquitectura inapropiada, entonces, la asistencia individual se vuelve escasa y problemática. De nuevo podemos ver aquí que si tal pedagogía aspira a ser implementada con éxito, necesariamente, requiere mínimamente de las mismas condiciones físicas de la escuela de clase media. La pedagogía invisible es una pedagogía costosa porque tiene su origen en una clase costosa: la clase media.

Desde el punto de vista de la clase media, existe, al menos, una comprensión intelectual de la pedagogía invisible, aunque, no siempre existe una aceptación de sus valores y prácticas. Además, si el niño de clase media no adquiere las competencias básicas a la velocidad que la madre espera, puede organizarse un sistema de ayuda educativa a través de clases privadas o mediante el propio esfuerzo de la madre. Las relaciones de poder entre la madre de clase media y el maestro están menos inclinadas en favor del maestro. Finalmente, la madre de clase media siempre tiene la opción de la escuela privada o de vivir cerca de la escuela estatal de su preferencia. Sin embargo, debido al concepto que la madre tiene sobre la función de la escuela secundaria, es probable que se preocupe más por la adquisición de las competencias básicas de su hijo y esto la ponga en conflicto con la escuela en algún momento.

Finalmente, debido a que el status de edad y el status de género están fuertemente clasificados y ritualizados dentro de la familia, es posible que la adquisición, progreso y evaluación de las competencias obtenidas en la escuela lleguen a formar parte de sus marcadores de edad y género. Así, por ejemplo, existe un cambio radical en el status y en el concepto de niño cuando éste se transforma en alumno. Ahora bien, en la medida en que la escuela infantil y la escuela primaria dejan de utilizar la edad y el género como categorías clasificatorias para la asignación de alumnos a grupos y espacios o, para la adquisición y progreso de las competencias, la escuela debilita la función de estas categorías en la familia y en la comunidad. Las pedagogías visibles no sólo refuerzan la clasificación de la edad y .el género sino que también proporcionan marcadores para evaluar el progreso dentro de éstos. Las pedagogías invisibles, posiblemente debilitan tales clasificaciones y, debido a esto, transforman el concepto de niño y los conceptos de status, de edad y género.

\section{Clase, Pedagogía y Evaluación}

El sistema de evaluación de los alumnos da origen a interesantes interrogantes. Allí donde la pedagogía es visible existe una red "objetiva" para la evaluación de los alumnos en la forma de (a), criterios claros y (b), delicados procedimientos de medición. El niño recibe una calificación o su equivalente por cada actuación evaluada. Además, cuando la pedagogía es visible, ésta posiblemente se estandariza y, en consecuencia, las escuelas se comparan directamente en relación con sus éxitos o fracasos. El perfil del alumno se puede obtener mediante el examen de sus calificaciones. El alumno sabe dónde está, el maestro sabe dónde está y, en consecuencia, los padres también saben dónde están. Los padres tienen su medida para comparar la escuela. Cuando el niño cambia de escuela se le asigna un lugar de acuerdo con su perfil académico. Además, para los padres es difícil estar en desacuerdo con el perfil porque éste es "objetivo". Evidentemente, existen elementos subjetivos en la evaluación de los niños, pero éstos están enmascarados por la aparente objetividad de la "red". En el caso de la pedagogía invisible no existe tal red. Los procedimientos de evaluación son múltiples, difusos y no están sujetos fácilmente a mediciones aparentemente precisas. Esto conduce a comparaciones entre el complejo de 
alumnos y también a comparaciones entre las escuelas ${ }^{37}$. En primer lugar, la pedagogía invisible no está basada en el progreso del grupo sino en el progreso de la persona. En segundo lugar, existen, probablemente, variaciones considerables entre los grupos preescolar e infantil dentro de la forma general de esta pedagogía. Para la pedagogía invisible existe menos dificultad para asignar al niño un lugar en una nueva escuela porque no existe un lugar explícito para él. En esta forma, la madre estará en menor capacidad para diagnosticar el proceso del niño y como consecuencia no puede proporcionar una ayuda educativa específica ${ }^{38}$. La madre estaría obligada proporcionar un medio educativo general en el hogar y sólo sería capaz de hacerlo si hubiera internalizado completamente las bases teóricas de la pedagogía invisible. Como hemos planteado anteriormente, este caso es menos probable allí donde los padres son de clase obrera. Así, pues, estos padres son aislados del proceso de evaluación de sus hijos y son forzados a aceptar lo que para el maestro cuenta como progreso.

Debido a que existe una red aparentemente objetiva para la evaluación de las pedagogías visibles, dicha red actúa selectivamente sobre aquellas disposiciones del niño que pueden ser objeto de clasificación por parte del maestro. Es claro que la motivación y el interés posiblemente son relevantes para cualquier pedagogía, pero su significado y consecuencias variarán de acuerdo con el tipo de pedagogía. En el caso de las pedagogías visibles la conducta del niño está centrada en el maestro de tal forma que la atención y la cooperación con éste se vuelven relevantes. La perseverancia y el cuidado también son evaluados por el maestro. Además, es posible que haya un conflicto entre el perfil académico del alumno y la evaluación que el maestro haga de sus actitudes y motivación. Los criterios objetivos y subjetivos pueden tener consecuencias diferentes para grupos de alumnos de clase social diferente. Es probable que ambos criterios sean comprendidos por los padres de clase obrera independientemente de su validez. Dado que en el caso de la pedagogía invisible un mayor número de características del niño son susceptibles de ser observadas y dada la existencia de nuevas pautas de interpretación, diagnóstico y evaluación, una clase diferente de actos y disposiciones del niño se vuelven relevantes. Mientras que en el caso de las pedagogías visibles la atención del niño se centra sobre el maestro, en las pedagogías invisibles la atención del maestro se centra sobre la totalidad del niño, esto es, sobre su hacer (actividad) y no-hacer (inactividad). Esto puede conducir a discrepancias entre la visión del maestro y la visión de los padres con respecto al niño, a no ser que los padres compartan la teoría del maestro. Más aún, es posible que las disposiciones y actos que están sujetos a evaluación por parte del maestro sean considerados como irrelevantes, innecesarios e incorrectos. Cuando esto ocurre, la conducta del niño se modela a partir de criterios en conflicto. Desde el punto de vista del maestro, el niño se convierte en un mensaje innovador para el hogar. La pedagogía invisible no es únicamente un sistema interruptor en el contexto de la práctica educativa, sino que también, bajo ciertas condiciones, convierte al niño en un mensaje innovador para la familia.

Es muy probable que esta pedagogía conduzca a un cambio en los procedimientos objetivos y subjetivos de la evaluación. Allí donde la pedagogía es visible existe un perfil que está compuesto por la evaluación de competencias específicas y un perfil que se compone de la evaluación de la motivación y actitudes de trabajo del niño. Es probable que este último esté compuesto de juicios estereotipados, más bien cortos y faltos de explicación. En el caso de las pedagogías invisibles estos juicios altamente condensados, escasos de sustentación y hechos públicos son remplazados probablemente por algo semejante a un dossier el cual incluye una gran variedad de procesos y estados internos

\footnotetext{
${ }^{37}$ Paradójicamente, esta situación conlleva su potencialidad para incrementar la competitividad.

${ }^{38}$ Ella puede ofrecer, por supuesto, elementos de una pedagogía visible.

Digitalizado por RED ACADEMICA
} 
del niño así como de sus actos externos. También es probable que la conexión entre lo interior y lo exterior se haga explícita. En otras palabras, es posible que exista una historia elaborada explícita de la relación entre los estados internos del niño y sus actos. En este caso es posible que se presente en la escuela el problema del cuidado de la información (su manejo secreto). ¿Hasta dónde debe profundizar el dossier? ¿Dónde se debe guardar? ¿Hasta dónde y en que forma pueden sus contenidos estar a disposición de los padres o de otras personas, dentro y fuera de la escuela? Como se observa, las pedagogías invisibles también pueden generar formas y contenidos de evaluación abiertos y ocultos. Tal sistema de evaluación aumenta el poder del maestro al punto que su teoría subyacente puede llegar a no ser compartida por los padres, y aun, cuando éstos la compartan.

Finalmente, el análisis más importante de esta sección ha sido el de las pedagogías idealizadas. Sin embargo, si el argumento de que puede existir en las formas de socialización una disyunción entre etapas primaria y secundaria, o entre etapas secundaria y terciaria, es correcto, entonces, se puede pensar que detrás de una clasificación y enmarcación débiles bien puede existir una clasificación y enmarcación fuertes. Así, podemos tener una situación donde $\mathrm{Cs}^{*}$ y Es fuertes suceden a Cs y Es débiles, o donde Cs y Es débiles suceden a Cs y Es fuertes, como, posiblemente ocurre en el caso de la formación de docentes para la escuela infantil en Inglaterra. Es importante no sólo entender la continuidad en la fuerza de la clasificación y enmarcación sino también entender la disyunción y cuándo esta disyunción ocurre. Es más que probable que si examinamos empíricamente las pedagogías invisibles, nosotros encontraremos diferentes grados de énfasis en la transmisión de competencias aisladas específicas. De esta manera, el "currículum oculto" de las pedagogías invisibles bien puede ser, inicialmente, el de una clasificación fuerte aunque con una enmarcación relativamente débil. Desde este punto de vista, es importante investigar qué niños o grupos de niños son particularmente receptivos (sensibles) a este "currículum oculto". Es un hecho que algunos niños pueden llegar a ver o ser orientados a ver que hay dos formas de transmisión, una abierta y otra oculta (encubierta) que se encuentran entre sí en una relación de figura-fondo. Necesitamos, entonces, saber -para qué maestros y para qué niños - cuál es la figura y cuál es el fondo. Específicamente, ¿pueden los niños de clase media reaccionar más a la pedagogía visible latente, o existen más posibilidades de que sean seleccionados como receptores? ¿De igual forma, pueden los niños de clase obrera baja reaccionar más a la pedagogía invisible o aceptar una forma más débil de la transmisión de la pedagogía visible? Es muy posible que el "currículum oculto" de las pedagogías invisibles sea una pedagogía visible. Sin embargo, los resultados de la inclusión de una pedagogía en la otra probablemente sean diferentes a los resultados que se producen en el caso de la transmisión de cualquiera de las pedagogías (visible o invisible). Desde un punto de vista más teórico, el componente crucial de la pedagogía visible es la fuerza de su clasificación pues en última instancia es ésta la que produce lo que cuenta como propiedad privada, y al hacerlo, regula la modalidad de socialización dentro de la clasificación. En el microcosmos de la guardería o de la clase infantil podemos ver, en su estado inicial, las nuevas formas de transmisión de relaciones de clase.

Tomemos un ejemplo concreto para ilustrar las especulaciones anteriores:

Un maestro de una escuela infantil en Inglaterra puede experimentar las siguientes conjunciones o disyunciones en su socialización:

\footnotetext{
${ }^{*} \mathrm{Cs}=$ Clasificaciones.

Es $=$ Enmarcaciones.

Digitalizado por RED ACADEMICA
} 
1) Entre la socialización en la familia y entre la escuela primaria y la escuela secundaria.

2) Entre las escuelas secundarias y la formación docente. Entre más alto sea el grado de calificación requerido por las instituciones universitarias de educación, más probable será que la socialización en los últimos años de la escuela secundaria se realice mediante clasificación y enmarcación fuertes. Por otra parte, la socialización en los institutos universitarios de formación de docentes puede darse dentro de una variedad de fuerzas en la clasificación y en la enmarcación.

\section{Transición entre etapas educativas}

Hemos examinado algunos aspectos de la transición a la escuela. Existe además el problema de la transición entre etapas educativas: del pre-escolar a la primaria, de la primaria a la secundaria, etc. La transición entre estas etapas está marcada por tres rasgos inter-relacionados:

1) Un incremento en la fuerza de la clasificación y enmarcación (iniciación dentro del código agregado).

2) Un incremento en el número de maestros; esto quiere decir que el alumno se hace consciente de los aislamientos producidos dentro de la división social del trabajo. El alumno también aprende que el principio de autoridad trasciende los individuos que lo detentan, pues, mientras que los maestros y las materias cambian su rol se mantiene igual.

3) La clasificación y enmarcación débiles de la pedagogía invisible enfatizan en la importancia de las formas de conocer, de construir problemas. Al contrario, la clasificación y enmarcación fuertes de la pedagogía visible enfatizan en estados de conocimiento y en la recepción de problemas (adquisición de resultados).

Así, hay un cambio fundamental en lo que cuenta como adquisición del conocimiento, en lo que cuenta como manifestación legítima de ese conocimiento y en lo que cuenta como contexto social. En una palabra, el cambio de las pedagogías invisibles a visibles es un cambio en el código, un cambio en los principios de relación y de evaluación, ya sean estos, principios del conocimiento, de las relaciones sociales, de las prácticas, de la propiedad, y de la identidad.

Es posible que este cambio en el código se realice de manera más efectiva (a pesar de las dificultades) por los niños de clase media porque su propia socialización dentro de la familia contiene ambos códigos -el código que crea la manifestación de la persona y el código que crea la propiedad privada. Además, como hemos planteado en alguna otra parte, es más posible que los niños de clase obrera experimenten continuidad en el código entre las etapas educativas. Sin embargo, el prejuicio de clase del código agregado (que crea una pedagogía visible) puede dificultar la recepción y explotación de la transmisión. En consecuencia, la continuidad de la pedagogía invisible en la forma de un código integrado así como su institucionalización en el nivel secundario, es más probable entre niños de clase obrera.

Podemos comenzar a ver que las condiciones para la continuidad del código educativo para todos los niños, independientemente de su clase social, es el tipo de código transmitido por la universidad. La simple expansión de la universidad, el incremento en la diferenciación del nivel terciario, la democratización de oportunidades de ingreso y egreso 
no cambiarán fundamentalmente la situación en los niveles inferiores. Con esto sólo habremos expandido el tamaño de la cohorte en el nivel terciario. Desde otro punto de vista, aunque se haya cambiado la estructura administrativa no se ha cambiado el código que controla la transmisión. En esta forma, el proceso de reproducción no se afectará fundamentalmente. Para cambiar el código que controla la transmisión se necesita cambiar la cultura de la clase basada en relaciones de clase privatizadas. Así, si aceptamos en favor de nuestro argumento el gran valor educativo de las pedagogías invisibles y de la clasificación y enmarcación débiles, la condición para su total y efectiva institucionalización en el nivel secundario, la constituye un cambio fundamental en el nivel terciario. Si esto no ocurre, entonces códigos y clase permanecerán firmemente ligados en la escuela.

Finalmente, podemos plantear una pregunta básica. El movimiento hacia las pedagogías invisibles realizado mediante los códigos integrados puede ser visto como una solución superficial a un problema más difícil de resolver. Los códigos integrados son integrados a nivel de ideas. Ellos no envuelven integración a nivel de instituciones como por ejemplo la integración escuela-trabajo. Sin embargo, la integración crucial es precisamente aquella que se da entre los principios de la educación y los principios del trabajo. En las sociedades occidentales (para mencionar sólo un grupo) no puede existir tal integración porque el trabajo es el epítome de las relaciones de clase. El trabajo únicamente puede penetrar la escuela en términos de la función que ésta cumple como un mecanismo de selección, o en términos de un ajuste psicológico o social al trabajo. En realidad, la abstracción de la educación del trabajo, que constituye el rasgo fundamental de la tradición liberal, o la relación entre educación y goce, enmascaran el hecho brutal de que la educación y el trabajo no pueden integrarse a nivel de los principios sociales en las sociedades de clase. La educación y el trabajo pueden estar separados o pueden articularse mutuamente. Durkheim escribió que los cambios en la pedagogía eran indicadores de una crisis moral. Tales cambios pueden enmascarar la crisis o cambiar su forma. Sin embargo, debido al hecho que el cambio a clasificación y enmarcación débiles tiene la potencialidad de reducir los aislamientos en las estructuras mentales y en las estructuras sociales y la potencialidad de hacer explícito lo implícito, tal código presenta la potencialidad de hacer visibles las contradicciones sociales fundamentales. 